International Journal of Educational Research 45 (2006) 404-419

\title{
Challenges in operationalizing cultural practices in classroom and peer communities
}

\author{
Nancy Ares* \\ Warner Graduate School of Education and Human Development, University of Rochester, P.O. Box 270425, \\ Rochester, NY 14627, USA
}

Received 28 February 2007; accepted 5 March 2007

\begin{abstract}
This paper explores challenges encountered in a study of culturally relevant pedagogy that examines numeracy practices of under-served youth in secondary mathematics classrooms and in their peer communities at school. Taking a sociocultural stance toward studying under-served youths' cultural practices as valuable resources for mathematics learning poses several methodological challenges, including identifying distinct cultural groups; adopting a view of mathematics as a social practice; and examining youth cultural practices to identify what counts as a viable example of practice relevant to mathematics practices and knowledge. Two dimensions of cultural practices are the focus: (1) communication, interaction, and language-use patterns that youth develop as they engage in the cultural practices of their peer communities; and (2) mathematical funds of knowledge that youth have developed over time. The complexities of identifying mathematical practices in youth peer communities and leveraging them in schooled mathematics are discussed, as are implications for further research.
\end{abstract}

(C) 2007 Elsevier Ltd. All rights reserved.

\section{Introduction}

This paper explores methodological challenges encountered in a study of numeracy practices of under-served ${ }^{1}$ youth in secondary mathematics classrooms and in their peer

*Tel.: + 1585273 5957; fax: + 15854737598 .

E-mail address: Nancy.Ares@rochester.edu.

${ }^{1}$ I use varying adjectives throughout the paper to refer to youth and communities that have and continue to be subject to societal inequities as a way to problematize what Lee (2003) points to as "current terminologies 
communities at school. The aim of the study is to inform theory and practice of culturally relevant pedagogies in classrooms using a new generation of networked ${ }^{2}$ technologies designed to leverage the power of groups in supporting mathematics learning (e.g., Texas Instruments' Navigator $^{\text {TM}}$; Participatory Simulations, Wilensky \& Stroup, 1999; SimCalc MathWorlds, Hegedus \& Kaput, 2002). Culturally relevant in this case means design and use of technology that:

- uses the cultural practices of students as valuable, legitimate resources for learning;

- treats use of those practices as central issues in design and implementation; and

- scaffolds students' learning of academic content by drawing on those practices in service of generative learning.

Thus, a central tenet of culturally relevant pedagogy is that identifying and drawing on the resources non-dominant youth develop as members of cultural groups is key to supporting their academic success.

Culturally relevant pedagogy is important because it treats the cultural practices students develop in their home and peer communities as crucial learning resources rather than barriers to success in school. Those resources are central to youths' cultural identities, cultural competence in their communities of origin, as well as their academic success (Lee, 2003). Developing methodologies to examine cultural relevance in design and use of educational technologies is critical to those technologies' inclusive impact in today's classrooms. As with many innovations, there has been a lack of attention to the influence of culture in network-mediated learning, to youth having varied ways of approaching tasks, and to the potential for simply exacerbating inequities in opportunities to learn and perform (Lee, 2003; Panofsky, 2003; Wilcox, 1988). Clearly, all classrooms involve cultural practices. However, looking at how under-served students are invited to bring to bear a variety of repertoires of practice in technology-supported activity will increase the likelihood that cultural relevance will be pursued as design of learning environments proceeds.

I present particular methodological challenges that have emerged in the study described here as I have worked to respond to a call issued by Carol Lee in a 2003 special issue of the Educational Researcher. In that issue, she urged the field to consider new ways of addressing race and ethnicity in our scholarship. In studying learning and development of groups whom face institutional and other racism, intergenerational poverty, and differential access to resources (e.g., schooling, health care, housing), she asks, "How do we resist simplistic assumptions about the meaning of group membership and develop more nuanced and complex research agendas that work from a basic assumption that human beings always have agency, always have resources, and make meaning of their experiences in varied ways?" (p. 4). Addressing Lee's question in pursuing culturally relevant pedagogy poses numerous methodological challenges, some of which are explored

\section{(footnote continued)}

(e.g., inner city, at risk) [that] carry with them similar sets of assumptions that continue to place groups in hegemonic opposition... to use any of the current terms inadvertently communicates the assumptions of privilege against which we argue" (p. 3).

${ }^{2}$ Networked technologies in this case are computers and/or calculators that link individuals in classrooms so that information can be aggregated as well as mutually exchanged and accessed, as well as displaying aggregated inputs from individuals in a visual projection that all can see. 
here in hopes of elaborating what is involved in re-conceptualizing issues of race and culture in educational research. In particular, I explore issues of identifying distinct cultural communities and their practices, adopting a sociocultural conception of mathematics, and the relationship between mathematics learning and youth peer communities' cultural practices. First, I describe the research study from which these methodological challenges emerge, including the relationship between culturally relevant pedagogy and the particular networked technology the project examines.

\section{The WideNet project: widening participation through networked technologies}

Rochester, NY is located in the northeastern US and is the state's third largest city. It has a city population of $\sim 220,000$ and a metropolitan population of $\sim 714,000$. Rochester ranks 11th in the country in the proportion of children living in poverty. The school district in which the study is located serves $\sim 34,000$ students. The school involved in this study has a heterogeneous demographic profile (60\% African American, 26\% Hispanic, 12\% White, 3\% Asian, Native American, Alaskan, and Pacific Islander; 11\% English language learners; $36 \%$ free or reduced lunch - a measure of socioeconomic status). Approximately 2200 students attend in grades 7-12.

My doctoral students, high school student co-researchers, and I are conducting studies in five high school mathematics classrooms and in sites outside classrooms. Those sites include the Commons Area of the high school where youth regularly play Spades, ${ }^{3}$ a 4-person, 2-team card game; the soccer and basketball teams' practices and games; and the school's Step ${ }^{4}$ Team practices and performances. Research in classrooms is designed to build understanding of network technology-mediated classroom processes (described below) important to leveraging cultural practices of underrepresented students. Work in sites outside classrooms aims to build understanding of social and cultural practices of youth peer communities at school, and to identify features of those practices that may be important in design and use of culturally relevant network-mediated activities in mathematics. Video- and audio-taped discourse and interaction, as well as individual and focus group interviews with teachers and youth, provide the data corpus for studies of both contexts.

\subsection{Theoretical framework}

We adopt a sociocultural perspective in this project, seeing this as a fruitful framework for re-conceptualizing issues of culture and race in the study. From that point of view, cultural practices are seen to include ways of interacting, reasoning, and using language and tools developed through engagement in everyday, historically inherited activities of

\footnotetext{
${ }^{3}$ Similar to Bridge, it is a trick-taking game (four cards/trick, 13 tricks per deck) in which "every player puts one card from his or her hand into play. ... Once each player has played a card to the trick, they are turned face down and removed from play" (http://en.wikipedia.org/wiki/Trick-taking_game). Spades 'trump' or outrank all other suits in taking tricks (although rules can vary); the higher cards within suits outrank lower cards (e.g., king outranks 10).

${ }^{4}$ Step is a form of dance important in African American communities, particularly sororities and fraternities, that involves groups' precisely coordinated, intricate arm and leg movements, loud stomping/marching, chants, and music. Its beginnings have been traced to the South during slavery, where it served as a link to African tribal dance and a means of retaining cultural practices in the face of oppression (Malone, 1996).
} 
communities (e.g., Lee, 2003; Scribner \& Cole, 1981). They also involve modes of, for example, interrelating with children and adults; communicating information, ideas and emotion; and approaching tasks. As a result of participation in communities' activities, youth develop community-specific repertoires of practices that influence their interactions in varying settings (e.g., home, school) and that serve as resources for learning, whether that learning is at school or elsewhere. Importantly, "[b]y focusing on the varied ways people participate in their community's activities, we can move away from the tendency to conflate ethnicity with culture, with assignment to ethnic groups made on the basis of immutable and often stable characteristics such as Spanish surname or country of birth" (Gutierrez \& Rogoff, 2003, p. 21). Instead, the focus is on how communities' shared practices develop through participation in everyday activity and interaction. Rather than treating culture as a static entity (e.g., learning styles), this approach acknowledges that culture is complex, multi-dimensional, and constructed through engagement in the activities of communities.

For this paper, two dimensions of cultural practices are the focus: (1) youth peer communities' communication, interaction, and language-use patterns (i.e., Lee, 1997, 2003); and (2) funds of knowledge (Gonzalez et al. 1995; Greenberg, 1989; Moll \& Greenberg, 1990) that youth have developed over time: “...the information, methods of thinking and learning, and practical skills related to a community's everyday life. ... a way of using social, physical, spiritual, and economic resources to make one's way in the world" (Leighton, Hightower, \& Wrigley, 1995, p. 83). In thinking of mathematical funds of knowledge specifically, youth may, for example, assist in their family's regular yard sales (Gonzalez \& Moll, 2002) or a Girl Scout club's cookies drive (Rogoff, 1995). Aspects of cultural practices in both cases involve mathematical concepts and skills (e.g., pricing, profit and loss, making change). In addition, communicating with peers and adults in these activities involves skill in using language to explain mathematical practices and processes; such cultural practices are important in making mathematical claims and offering proof or evidence to support them. In addition, yard sales in Mexican American neighborhoods in Tucson, Arizona and cookie drives among White middle class families in Salt Lake City, Utah engage youth in cultural practices that are grounded in specific ethnic/racial communities in particular geographic regions of the US. Thus, for the research described below, cultural practices that have mathematical dimensions and that have developed from specific communities' sociocultural evolution are the focus of our work to bridge youth peer community and networked classroom practices.

\subsubsection{The networked classroom context}

The particular classroom technology this project uses is HubNet and Participatory Simulations (Wilensky \& Stroup, 1999, 2000), run on Texas Instruments' Navigator ${ }^{\text {TM }}$ system. The system involves graphing calculators connected to a central computer that collects data from the individual devices. A principle design feature of this networked technology is leveraging the power of group interaction in learning. Students use calculators to act as individual agents who contribute to the emergence and evolution of a shared mathematical object and/or complex dynamic system that is projected in real time in a publicly displayed space for all to see (see Fig. 1). The software and the curricular activities require that students collaborate for the activities to proceed. For example, one of the simulations involves individual students controlling stoplights at intersections in a traffic grid, with the whole group being responsible for optimizing traffic flow as measured 


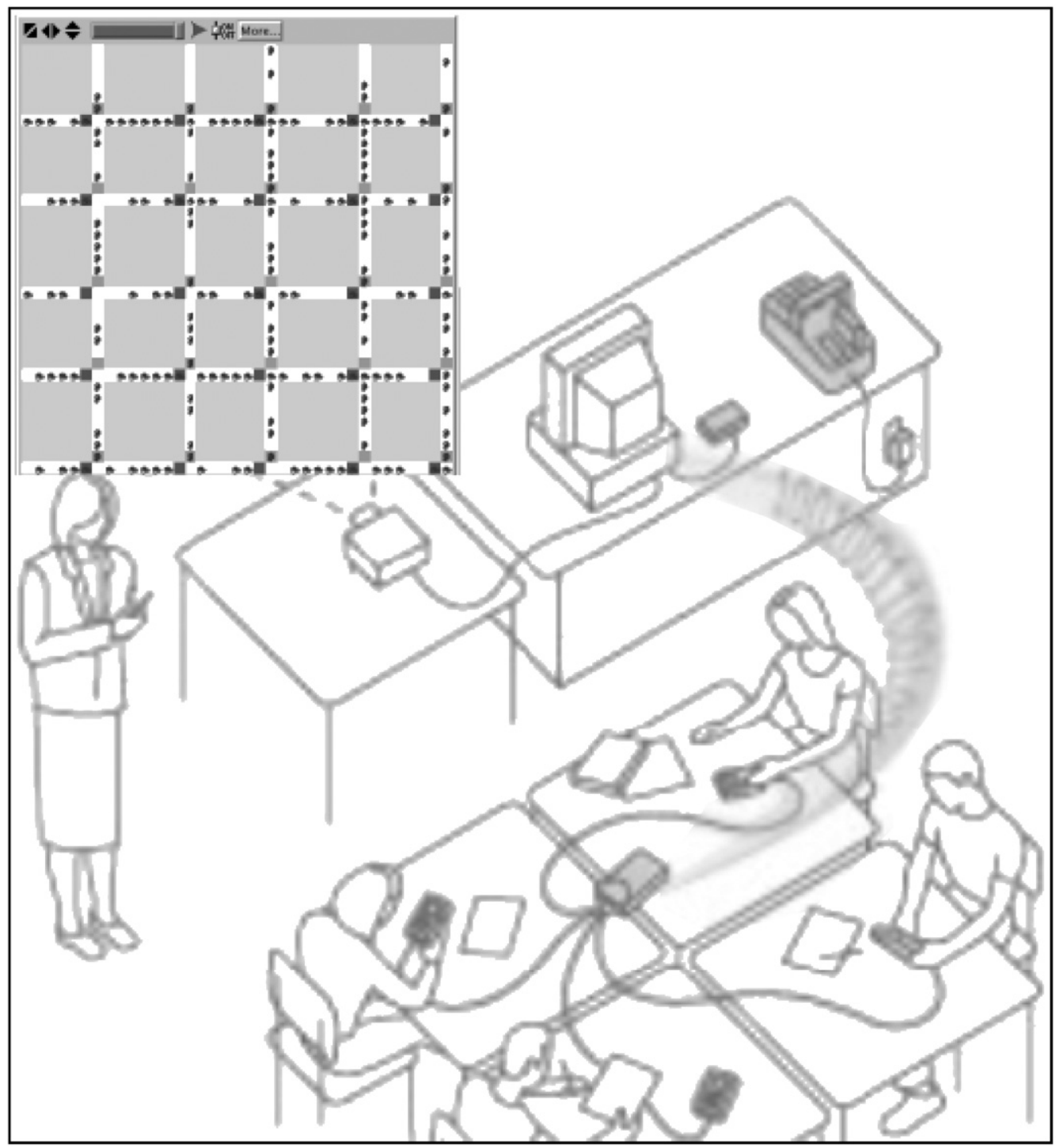

Fig. 1. Graphing calculators are connected to wireless hubs that communicate with a computer that functions as central server. Individual student inputs are collected and together create an emergent system that is displayed up front.

by metrics of speed, wait time, and number of stopped cars over time. The graphs of the metrics of traffic flow are displayed in real time as the simulation proceeds, and provide a focus of discussion that links the graphs to each other and to the flow of traffic in the grid. These discussions and analyses engage students in important mathematical discourse, reasoning, and practices-hypothesizing, analyzing graphs, relating graphical and symbolic representations, predicting, and abstracting - about challenging curricular topics including relationships between rate and amount, and linear and more complex functions (Ares, in review; Ares, Stroup, \& Schademan, in review; Stroup, Ares, \& Hurford, 2005). 
Particular features of these network-mediated, participatory activities offer potentially important avenues for enlarging the types of cultural practices used as resources for learning: (1) multiple modes of contribution (language, text, physical and electronic gestures); (2) multiple representations of phenomena (texts, graphs, visual displays of emergent systems, language); and (3) inquiry-oriented discussion and analyses important to the practice of mathematics. The discussions are similar to "metacognitive conversations... in which students are supported in making public the strategies they are employing as well as the evidence and reasoning they are using, ... [and] where instructional conversations are not solely directed by teachers' intentions" (Lee, 2003, p. 48, 49). These discussions promote a balance between teacher and student talk that, combined with the multiple modes for participating in the discussions, provide a multidimensional space in which students can act (Ares, Stroup, \& Schademan, 2004). Further, the availability of linked graphical and other representations in the visual display provides diverse tools on which students can draw as they engage in the networked activity. The important point is that there is invitation and opportunity that enlarges the space of possibilities for participation.

\subsubsection{Findings}

In the youth peer community sites, preliminary analyses illuminate the pervasiveness of mathematics embedded in everyday activities. Students have turned our attention to such things as team and role-playing card games (e.g., Hearts, Spades, Tunk, Pokemon, Magic, Yuggio), role-playing and other video games (Star Wars, Guild Force, Sim City, Mortal Combat), and dieting as regular activities that involve mathematics. Specific mathematical content ranges from ratio and probability, relative values (among video game characters: life points in relation to power levels, time to swing in relation to number of blows landed needed to win), averages, as well as relationships among velocity, distance, and time to finish. Importantly, social aspects of everyday mathematics practice are also being explicated, particularly task-focused goals rather than the displays of competence often emphasized in school settings (see Nunes, 1995 for more extensive treatment of social aspects of mathematics activity; also Street, Baker, \& Tomlin, 2005). The richness of the mathematics involved and youths' willingness to participate in mathematical activity is enhanced, according to student interviews from the WideNet Project and corroborated in Gee's (2003) examination of learning in video games, by the engaging, challenging, and creative nature of these activities.

In pursuing culturally relevant network design and use, we are conducting an extensive study of Spades play, charting its historical development in the African American community, explicating the mathematics involved (e.g., risk assessment, probabilities), and examining youths' purposes for playing (Schademan \& Ares, 2006). Those purposes include fun and relaxation, but also displays of mathematical prowess, creativity in changing the rules of the game, and dramatic performance (the physical and verbal aspects of play).

Understanding of the mathematical and social aspects of the game of Spades is critical to our connecting this culturally valued, mathematically rich practice to classroom mathematics teaching and learning through our development of a Spades Participatory Simulation for use in the WideNet mathematics classrooms.

Prior findings from the classroom sites indicate that the real-time visual display and whole-class analysis of the emerging complex system are crucial features in increasing the 
numbers of students participating, in classes' engagement in academic mathematical discourse and practices, and in fostering a balance between student and teacher talk (Ares et al., 2004, in review). Networked technology-supported classroom activity increased the visibility of students' reasoning, connected to students' lived experiences, and leveraged every student's participation, broadening significantly the opportunities for underrepresented students' cultural resources to be treated as valuable contributions to classroom learning. Finally, students and teachers reported that the collaborative focus and opportunities to work together invite students to participate, creating an atmosphere of relaxed interdependence (Ares, in review; Ares et al., 2004). Given these characteristics of design and use, classrooms using these technologies provide important, unique contexts for examining participation of non-dominant students and issues of culture in design and use of educational technologies. However, for both youth peer communities and networked classrooms, several methodological challenges must be addressed to understand and pursue culturally relevant pedagogy in these contexts in a way that responds to Lee's call for re-conceptualizing issues of culture and race in educational research.

\section{The challenges}

A central challenge in this project is that I am a middle class, white researcher, conducting a study of under-served youth who are from different cultural and class backgrounds from my own. Critical issues of power, status, position and understanding are involved. To address these issues, I have assembled a multicultural team that includes African American, Guatemalan, Greek, and White men and women doctoral students. In addition, we involve high school students from the classrooms in which we are conducting the studies as co-researchers; those students are of African American (8), Puerto Rican (2), European American (1), Nigerian (1), and mixed race descent (Korean/Caucasian) (1). The aim is to increase the trustworthiness of the analyses and findings by drawing on multiple and "insider" perspectives. The high school students pose their own research questions related to the WideNet project, and collaborate with us in study groups, following Moll, Gonzalez and colleagues' work in funds of knowledge (cf., Gonzalez et al., 1995), during which we analyze data to identify social and cultural practices (e.g., use of signs and symbols, artifacts and tools, social relations) that distinguish communities and features of which may be important in increasing the cultural relevance of the design and use of the networked technology in mathematics classrooms.

Other methodological challenges in this work center on operationalizing peer community cultural practices and understanding them in relation to classroom mathematics learning. I explore these tasks first in relation to the study's methodology designed to examine cultural practices across peer and classroom communities, and then in relation to operationalizing cultural practices in relation to mathematics.

\subsection{Locating cultural practices}

There is danger in identifying cultural practices in that groups and their activities can be essentialized, as in some work in learning styles that painted whole groups in homogeneous terms (all Black students prefer to work in groups; all Native American students avoid eye contact). Instead, sociocultural theory "leads us to expect regularities in the ways cultural communities organize their lives as well as variations in the ways individual members of 
groups participate and conceptualize the means and ends of their communities' activities" (Gutierrez \& Rogoff, 2003, p. 22). Those regularities and variations can be characterized as repertoires of practices that people develop through participation in a community (e.g., observing, producing and reproducing ways of participating). The notion that both local and broader cultural activity is important to understanding cultural practice is helpful in examining regularities and variations in cultural practices. It leads to methodologies that attend to multiple levels of activity and varying spans of time to characterize individuals' and groups' prior experience with particular community cultural practices, as well as development over time of the practices themselves (e.g., "nature and forms of cultural artifacts and tools used; the social relations, rules, and division of labor; and the historical development of individuals and communities," p. 22). The tension and complexity of the task of operationalizing cultural practices that operate in different, overlapping spheres and across varying time scales poses important challenges to understanding the resources youths' peer and home communities develop through engagement in their locally and historically constructed practices.

For example, youth peer communities certainly provide opportunity for and exert local pressure on students to develop cultural practices, many of which involve mathematics (e.g., card and other games, sports, work). At the same time, youth "bring with them" practices of their home communities through which inter-generational practices have been appropriated and which influence their interactions and activities at school. Somewhat akin to Gutierrez and Stone's (2000) constructs of synchronic and diachronic dimensions of social practice, my students and I are examining youth peer communities' everyday cultural practices as emerging from youth sub-cultures that are tightly related to their home cultural communities' local histories in Rochester, NY and in the US. Challenges in identifying those communities are addressed next.

\subsubsection{Distinct cultural communities across settings and time}

High school youths' collaboration with us in making sense of their peer communities is our beginning attempt to address the multiple levels in which cultural practices and repertoires of practice are developing and operating. The student co-researchers working with us are from varied backgrounds, i.e., African American, Puerto Rican American, Nigerian; native of Rochester, first generation immigrant; lower middle class, living below poverty line; conservative, fundamentalist Christian, agnostic. This diversity in backgrounds and experiences reinforces the need for a methodology that captures the heterogeneity of youth peer communities and the shared repertoires they develop. Instead of continuing to rely on ethnicity, race and/or class to identify groups, the challenge is to discern what groups exist in a more grounded way. As we observe youth communities in the school and work with our student collaborators, we face several questions: what constitutes a distinct cultural community? And, what cultural practices hold a group together?

\subsubsection{What constitutes a distinct cultural community?}

Embracing the notion that practices develop through activity within and across varying contexts requires a methodological approach that recognizes local histories and interactions as well as influences of broader social, political, and cultural dimensions of human activity. Cole (1995) argues that, "culture comes into being wherever people engage in joint activity over a period of time" (p. 301), citing early work by Rose and Felton 
(1955) who examined small groups' work and found that "members quickly begin to invent new vocabulary and ways of doing things, primary and secondary artifacts" (p. 302). He also points to Fine's (1987) notion of idioculture, or the emergence of culture resulting from interactions within small groups:

a system of knowledge, beliefs, behaviors, and customs shared by members of an interacting group to which members can refer and that serve as the basis of further interaction. Members recognize that they share experiences, and these experiences can be referred to with the expectation they will be understood by other members, thus being used to construct a reality for the participants. (Fine, 1987, p.125, cited in Cole, 1995, p. 302)

Viewing youth peer communities as idiocultures is helpful in directing our attention to the ways in which local practices and interactions distinguish groups from each other.

In the WideNet Project, the notion of idioculture turns our attention to the local, daily interactions among youth peer communities whose activities have particular value in their home communities and involve particular patterns of language use, gesture, and discourse in their communities in Rochester, NY. ${ }^{5}$ For example, in the groups that play Spades regularly in the Commons Area of the school at lunchtime, field note data show that the fast pace of the game and the obvious expertise among the group members are distinctive. For example, when one girl played a card midway through a round, the rest of the group laid their cards on the table, knowing that her team would inevitably win. The practice of modifying rules to change "old school" Spades to the "new school" version played in the Commons Area also sets this community apart. The local practices, social relations (good players are high status, newcomers are tolerated if they are reasonably good), artifacts and tools, symbols and signs (throwing cards down hard on table and yelling as a sign of especially good play) resulted in the short-term, local emergence of culture, and were used for the groups' development of a collective sense of identity, as well as our identification of them as a distinct community.

Idioculture is helpful in examining groups closely, however, with this research project's focus on drawing on resources of under-served or marginalized groups, it is necessary to consider issues of race and ethnicity very explicitly as well. Thus, we are compelled to include students' experiences and shared histories as, for example, African Americans, Puerto Ricans, and/or youth living in poverty, and the development of those communities' practices over time in Rochester, NY. Somewhat in tension with the focus of idioculture on local emergence of culture, Gutierrez and Rogoff (2003, p. 21) argue that:

By cultural community we mean a coordinated group of people with some traditions and understandings in common, extending across several generations, with varied roles and practices and continual change among participants as well as transformation in the community's practices.

I have found it useful to make a distinction between social and cultural practices to link idiocultures with larger cultural communities. In this view, social practices involve the ways that people in groups behave and interact locally, as well as the ways groups organize themselves. In other words, actions involving relations of power, position, and normative behaviors are central to social practices. Cultural practices involve the patterns of behaving, interacting, and organizing relations of position, power, and normative

\footnotetext{
${ }^{5}$ Though, for Spades in particular, the practice at school is a contentious one, with some adults and youth in the community viewing it as a waste of time or an inappropriate school activity.
} 
behaviors that characterize a group. These are historically derived and culturally/ community-specific relations and patterns. Our attention to social practices of youth peer communities examines linkages to broader cultural practices. In Rochester, Spades and Stepping are African American cultural practices that involve social practices of youth, who reproduce and transform cultural practice (e.g., adapting "old school" rules for "new school" versions of Spades, introducing music and gestures from popular culture into Stepping routines). Combining reviews of the history of Spades and Step, interviews with our students about the sources of their understandings of those activities, and archival and other work to build an understanding of the history of African Americans in Rochester, $\mathrm{NY}$, we are working to link social and cultural practices, and, further, to understand how features of those practices are important in mathematizing activity.

\subsubsection{What holds groups together?}

Anderson (1991, as cited by Brunt, 2001) recommends analyzing communities based upon the "deep, horizontal comradeship that binds its members" (p. 83). Those binding forces can include shared meanings of sign and symbol systems such as language, flags, and other symbols, or the shared histories of people in relation to race, ethnicity, socioeconomic status or other shared experiences. These forces can help pinpoint practices that distinguish groups because they help identify how repertoires are developed through social interaction and how groups develop practices that distinguish them as unique.

Questions that we have confronted in this task center on how to determine what binding forces are operating in youth peer communities. Sociocultural theory directs our attention to both material and social dimensions of interaction that comprise binding forces, including the use of artifacts and tools, the social relations among peer community members, shared repertoires of practice, and the historical, social and political influences on the development of youth and their peer communities. This leads to examination of such things as use of signs and symbols (e.g., language, gesture); creation of local practices as derived from historically developed cultural practices; social relations, rules, and norms in community interaction patterns; and issues of race and class as features of the historical development of individuals and communities in Rochester, NY. In our study of Spades, the dramatic verbal and physical dimensions of the style of play, youths' modification of "Old School" to "New School" rules to increase the likelihood of winning by large margins, and players' pride in continuing a tradition learned in their home communities are binding forces that hold these groups together. For our research, they are crucial to grounding our identification of distinct cultural groups in everyday activities of youth.

Again, these methodological moves are aimed at addressing the complexity of the task of operationalizing cultural practices from a sociocultural point of view, one that pushes us to consider carefully the ways we are addressing race and ethnicity. That framework requires attention to youths' activities across varying contexts, as influenced by forces operating at varying time scales to understand the resources marginalized youth bring to school learning. Built on that work, to pursue cultural relevance in WideNet, we also must consider the mathematical dimensions of youth peer community practices.

\subsection{Operationalizing cultural practices in relation to mathematics learning and practice}

Vygotsky's (1987) argument that everyday and scientific concepts exist in dialectical relation to each other, that each contains elements of the other, is helpful in analyzing 
youths' everyday activity in light of formal mathematical learning. Extensive work in everyday and school mathematics has been pursued (e.g., Carraher, Carraher, \& Schliemann, 1985; Nunes, 1995; Saxe, 1991), illuminating the reasons practices in everyday contexts often do not travel successfully to school contexts. Those reasons include the different social meanings of practice in the two settings (display of understanding versus solution to a problem) and the varied influence of symbolic tools on intellectual activity (e.g., oral versus written mathematics). However, the challenge for the WideNet project is different, as the goal is to use marginalized youth peer community practices as resources for mathematics learning. This means that rather than identifying barriers to youths' drawing on out-of-school practices, the goal is to identify and operationalize practices that can be used as content-focused learning resources across contexts.

Lee's (1993, 2001, 2003) work on Cultural Modeling provides an important model for our work, in that she bases her literacy research and practice with African American high school students in Chicago on practices in scholarly literary analysis. Built on a deep understanding of those practices, she draws on the linguistic and interactional resources in African American Vernacular English, particularly those involved in signifying talk (e.g., metaphor, irony), as important tools for analysis of canonical texts. Gonzalez and Moll (2002), Gonzalez et al. (1995) and Moll et al.'s (1992) work on funds of knowledge is also highly influential, turning our attention to "the mathematical potential" of under-served youth peer community practices and to mathematizing those practices (Gonzalez, Andrade, Civil, \& Moll, 2001, p. 115).

A key methodological task we are confronting is that peer communities' practices need to be characterized with a specific eye to those that may support classroom mathematics learning in a networked learning environment. This task is required not only by the focus on mathematics learning, but also by the focus on cultural relevance that includes academic achievement as a central tenet (cf., Ladson-Billings, 1995). Two central questions then emerge: "What is our view of mathematics? Given that view, what counts as a viable example of practice relevant to mathematics practices and knowledge?'

\subsubsection{Conceptions of mathematics}

In sociocultural frameworks, mathematics is not viewed as a static, canonical discipline, but as discursive practice that affords agency to act and to produce knowledge. In this view, "students, rather than struggling with differences between the everyday and the mathematical registers... use resources from both registers... to communicate mathematically. A situated-sociocultural perspective thus moves away from the description of obstacles and deficiencies to a description of resources and competencies and widens what counts as competence in mathematical communication" (Moschkovich, 2002, p. 197). Gee's (1999) work is also helpful here in viewing mathematics as a semiotic domain, or a "set of practices that recruits one or more modalities (e.g., oral or written language, images, equations, symbols, sounds, gestures, graphs, artifacts, etc.) to communicate distinctive meanings" (p. 18). Mathematics learning and practice involve formal and informal mathematics, use of multiple representations of phenomena (e.g., graphs, written text, diagrams, notational systems, gesture, language), and such things as skills in argumentation, collaborating with colleagues, and building on crucial arguments. Further, beyond identifying specific mathematical content and interactional skills involved in everyday activity (e.g., cooperation, co-construction), identifying forms of mathematical 
reasoning (e.g., hypothesizing, predicting, strategizing; linking multiple representations of phenomena; proportional, algebraic, probabilistic reasoning), or mathematizing activity, is necessary. Sociocultural theory helps in focusing attention on the ways in which people make and do mathematics.

Conceptualizing mathematics broadly as a semiotic domain that involves a range of symbolic, linguistic, and interactional activities is important in widening what counts as mathematical competence and the kinds of activities treated as legitimate teaching and learning in school. Thus, academic achievement is measured not only by school-based and/ or state-mandated testing, but also by participation in powerful mathematical discourse. Given this broad definition of mathematics, we can turn our attention to the ways in which mathematics is integral to youth peer communities' practices, and to how use of those practices can support cultural relevance in networked technology design and use in mathematics classrooms.

We are just beginning to analyze mathematics discourse and practice in everyday activities of youth peer communities, with particular attention to interaction and language-use patterns, as well as to multimodality in mathematical practice and discourse, i.e., the use of gesture, everyday language, coordination of efforts and co-construction of mathematically rich objects and repertoires of practice. For instance, the performative aspect of Spades play evident in our data, confirmed in interviews with players, is important in providing a venue for displaying prowess, prowess built in part on a strong grasp of the deeply embedded mathematics, i.e., conditional probabilities, combination, remembering and recognizing patterns in previous plays, prediction, hypothesizing, strategizing. Further, salient features of the group whose regular practice was to play cards included such things as coordination of effort among team members to create strategies for winning and for determining the strength of competitors' hands, co-construction of rules for fair play, and use of informal language to communicate their probabilistic reasoning about whether they could win a certain number of rounds. Broadening our view of what counts as mathematics, mathematical communication, and mathematical competence also expands what can be viewed as viable examples of practice that are relevant to networked classroom learning.

\section{Discussion and conclusion}

In answering Lee's call to re-conceptualize issues ethnicity and race in educational research, I have explored developing a methodology focused on the relation between nondominant youth peer communities' cultural practices and the practices of mathematics classrooms, and the ways that culturally relevant design and use of new networked classroom technologies can optimize those relations in service of generative learning. This approach treats examining cultural practices, particularly in service of addressing inequities in schooling, as "not merely... helping minority students reach higher standards... but instead [as] a matter of understanding diversity as a relation between the community of practice established in the math classroom and the other communities of practice of which students are a part" (Nasir \& Cobb, 2002, p. 97). Though this study focuses on youth in the US, the methodological challenges posed are not limited to that context, as the focus is on youths' negotiation of multiple social and cultural contexts, something that is true worldwide.

However, the argument here is not that the challenges in pursuing culturally relevant pedagogy are universal. Educational innovations are often directed at all learners, rather 
than centering on particular cultural groups, producing supposedly generalized strategies to increase participation and success. In contrast, scholars working in culturally relevant pedagogy argue that, given the fact that cultural communities develop repertoires of practices through historically derived communication, interaction, and other patterned activity (Gonzalez \& Moll, 2002; Gutierrez \& Rogoff, 2003; Lee, 2001), generalization is impossible. An important move to make, I believe, is to follow Brenner's (1998) lead and not claim that these innovations are good for "all students," but to show the ways that they support learning of specific groups. As Lee (2003, p. 58) notes,

The dominant cognitive research literature on educational design rarely specifically addresses the significance of whether players are African American, Puerto Rican, Mexican American, or Laotian, whether those players are speakers of English or persons for whom English is a second language or who speak a "nonstandard" variety of English. However, I argue that who these people are, how they culturally identify themselves, is not an irrelevant consideration in our design decisions.

Focusing efforts on the repertoires of practice of particular communities has better chance to improve mathematics teaching and learning, and to realizing the potential of innovative classroom technologies. The goal here is to explore the challenges in developing a research methodology that aims to support efforts to draw on the particular cultural practices of specific marginalized groups and to foster students' and groups' increased agency and future success.

\subsection{Further questions we need to explore}

Rather than pose solutions, I offer challenges encountered and approaches my research team has undertaken to address those challenges. Clearly, much more work needs to be done to understand how sociocultural theoretical frameworks are helpful and the ways in which they need to be extended to illuminate processes and outcomes of youths' negotiating the varied contexts they encounter in their lives. The complexities of identifying mathematical practices in youth peer communities and leveraging them in schooled mathematics are daunting, given several factors. The kinds of mathematics and mathematical activity treated as valuable in schools is a contentious issue, as reformoriented standards put forth in the US by such organizations as the National Council of Teachers of Mathematics (NCTM, 2000) are being challenged by moves to more traditional notions in such federal education policies as No Child Left Behind. Similar challenges are found in the UK in the National Numeracy Strategy (Office for Standards in Education, Ofsted, 1996), as well as in New Zealand and Australia (Street et al. 2005). Teachers' willingness to consider widening the space of participation to include underserved students funds of knowledge and repertoires of practice is tempered by mandates to conform to narrower norms.

More important, though, from my project's point of view, is the question of what we are asking youth to allow in attempting increase the cultural relevance of mathematics practice in classrooms. Youths' social and cultural practices are value-laden, tied up with youth and community identities, and according to our student co-researchers, often engaged in at school as a way to create a safe space within an institution that makes them feel defensive. It could be presumptuous on our part to try to "use" these practices in design and use of 
classroom technologies. "Schooling" such practices has potential to co-opt them and to strip them of central features that make them valuable and important to youth.

Another crucial question applies to changing teachers' pedagogy. There is danger, as has been seen in learning styles research and practice, in work such as this leading to practitioners' and researchers' treatment of the results as prescription rather than description. Gutierrez and Rogoff (2003, p. 23) offer sage advice:

...focus on understanding developing individuals and changing communities, making first guesses about patterns and seeking confirmation or disconfirmation to extend what is known. Researchers thus need understanding of the practices under study, including an understanding of the relationship between a community's practices and the routine practices in which an individual participates. They would check their assumptions about an individual's familiarity with the focal practice as well as seek further information about whether and how an individual might participate in the practice.

Methodological challenges involved here include determining ways of presenting findings that resist essentializing groups; building relationships with participants that foster understanding of culture as dynamic, mutable, and evolving; and, though not a new challenge, continuing efforts to engage readers and participants in critical reflection on sources of marginalization and views of marginalized youth as able, as sources of insight and knowledge, and as agents of production of important knowledge.

\section{Acknowledgments}

The work of doctoral research assistants Dawn Evans, Peggy Postell, Al Schademan, Essie Sierra, and Eleanna Tsoumani is central to this work. Dawn Evans and Al Schademan are particularly important to helping conceptualize and design the methodology explored here.

\section{References}

Anderson, B. (1991). Imagined communities: Reflections on the origin and spread of nationalism. London: Verso.

Ares, N. (in review). Inviting participation: Cultural relevance in design and use of networked classroom technologies. Journal of the Learning Sciences.

Ares, N., Stroup, W. M., \& Schademan, A. (2004). Group-level development of powerful mathematical discourses: Networked classroom technologies as mediating artifacts. In Paper presented at the American Educational Research Association meeting, San Diego, CA.

Ares, N., Stroup, W., \& Schademan, A. (in review). The power of mediating artifacts in group-level development of mathematical discourses. Cognition and Instruction.

Brenner, M. E. (1998). Adding cognition to the formula for culturally relevant instruction in mathematics. Anthropology \& Education Quarterly, 29(2), 214-244.

Brunt, L. (2001). Into the community. In A. C. P. Atkinson, S. Delamont, J. Lofland, \& L. Lofland (Eds.), Handbook of ethnography (pp. 80-91). London: Sage.

Carraher, T., Carraher, D., \& Schliemann, A. (1985). Mathematics in the streets and in the schools. British Journal of Developmental Psychology, 3, 21-29.

Cole, M. (1995). Cultural psychology: A once and future discipline. Cambridge, MA: Belknap Press of Harvard University Press.

Fine, G. A. (1987). With the boys. Chicago: University of Chicago Press.

Gee, J. P. (1999). An introduction to discourse analysis: Theory and method. London: Routledge.

Gee, J. P. (2003). What video games have to teach us about learning and literacy. New York: Palmgrave. 
Gonzalez, N., Andrade, R., Civil, M., \& Moll, L. (2001). Bridging funds of distributed knowledge: Creating zones of practices in mathematics. Journal of Education for Students Placed At Risk, 6(1\&2), 115-132.

Gonzalez, N., \& Moll, L. C. (2002). Cruzando el puente: Building bridges to funds of knowledge. Educational Policy, 16(4), 623-641.

Gonzalez, N., Moll, L. C., Tenery, M. F., Rivera, A., Rendon, P., Gonzalez, R., et al. (1995). Funds of knowledge for teaching in Latino households. Urban Education, 29(4), 443-470.

Greenberg, J.B. (1989). Funds of knowledge: Historical constitution, social distribution, and transmission. In Paper presented at the Meeting of the Society for Applied Anthropological, Santa Fe, NM.

Gutierrez, K., \& Rogoff, R. (2003). Cultural ways of knowing: Individual traits or repertoires of practice? Educational Researcher, 32(5), 19-25.

Gutierrez, K. D., \& Stone, L. D. (2000). Synchronic and diachronic dimensions of social practice. In C. D. Lee, \& P. Smagorinsky (Eds.), Vygotskian perspectives on literacy research (pp. 150-164). New York: Cambridge University Press.

Hegedus, S., \& Kaput, J. (2002). Exploring the phenomena of classroom connectivity. In D. Mewborn, et al. (Eds.), Proceedings of the 24th annual meeting of the north American chapter of the international group for the psychology of mathematics education (pp. 422-432). Columbus, OH: ERIC Clearinghouse.

Ladson-Billings, G. (1995). Toward a theory of culturally relevant pedagogy. American Educational Research Journal, 32(3), 465-491.

Lee, C. D. (1993). Signifying as a scaffold for literary interpretation: The pedagogical implications of an African American discourse genre (Research Report Series). Urbana, IL: National Council of Teachers of English.

Lee, C. D. (1997). Bridging home and school literacies: A model of culturally responsive teaching. In J. Flood, S. B. Heath, \& D. Lapp (Eds.), A handbook for literacy educators: Research on teaching the communicative and visual arts (pp. 330-341). New York: MacMillan.

Lee, C. D. (2001). Is October Brown Chinese? American Educational Research Journal, 38(1), $97-141$.

Lee, C. D. (2003). Toward a framework for culturally responsive design in multimedia computer environments: Cultural modeling as a case. Mind, Culture, and Activity, 10(1), 42-61.

Leighton, M. S., Hightower, A. M., \& Wrigley, P. G. (1995). Model strategies in bilingual education: Professional development. Washington, DC: Department of Education.

Malone, J. (1996). Steppin' on the Blues: The visible rhythms of African American dance. Urbana-Champagne, IL: University of Illinois Press.

Moll, L., Amanti, C., Neff, D., \& González, N. (1992). Funds of knowledge for teaching: A qualitative approach to developing strategic connections between homes and classrooms. Theory into Practice, 31(2), $132-141$.

Moll, L. C., \& Greenberg, J. B. (1990). Creating zones of possibilities: Combining social contexts for instruction. In L. C. Moll (Ed.), Vygotsky and education: Instructional implications and applications of sociohistorical psychology (pp. 319-348). New York: Cambridge University Press.

Moschkovich, J. N. (2002). A situated and sociocultural perspective on bilingual mathematics learners. Mathematical Thinking and Learning, 4(2\&3), 189-212.

Nasir, N. S., \& Cobb, P. (2002). Diversity, equity and mathematical learning. Mathematical Thinking and Learning, 4(2\&3), 91-102.

National Council of Teachers of Mathematics (2000). Principles and standards for school mathematics. <http:// www.nctm.org/standards >. Retrieved March 13, 2006.

Nunes, T. (1995). Cultural practices and the conception of individual differences: Theoretical and empirical considerations. In J. Goodnow, O. Miller, \& F. Kessel (Eds.), Cultural practices as contexts for development (pp. 87-102).

OFSTED. (1996). Successful teaching of literacy and numeracy in primary schools: A starting point. London: OFSTED.

Panofsky, C. P. (2003). The relations of learning and student social class: Toward re-"socializing" sociocultural learning theory. In A. Kozulin, B. Gindis, V. S. Ageyev, \& S. M. Miller (Eds.), Vygotsky's educational theory in cultural context (pp. 411-432). New York: Cambridge University Press.

Rogoff, B. (1995). Observing sociocultural activity on three plans: Participatory appropriation, guided participation, apprenticeship. In J. Wertsch, P. del Rio, \& A. Alvarez (Eds.), Sociocultural studies of mind (pp. 139-164). Cambridge, UK: Cambridge University Press.

Rose, E., \& Felton, W. (1955). Experimental histories of culture. American Sociological Review, $20,383-392$.

Saxe, G. (1991). Culture and cognitive development: Studies in mathematical understanding. Hillsale, NJ: Lawrence Erlbaum.

Scribner, S., \& Cole, M. (1981). The psychology of literacy. Cambridge, MA: Harvard University Press. 
Schademan, A., \& Ares, N. (2006). Playing Spades: The rich social and cultural practices of African American youth. In Paper presented at the Meeting of the American Educational Studies Association, Spokane, WA.

Street, B., Baker, D., \& Tomlin, A. (2005). Navigating numeracies: Home/school numeracy practices. Dordrecht, The Netherlands: Springer.

Stroup, W., Ares, N., \& Hurford, A. (2005). A dialectical analysis of generativity: Issues of network supported design in mathematics and science. Mathematical Thinking and Learning, 7(3), 181-206.

Vygotsky, L. S. (1987). Thinking and speech. In R. W. Reiber, \& A. S. Carton (Eds.), The collected works of L.S. Vygotsky (pp. 39-243). New York: Plenum Press.

Wilcox, K. (1988). Differential socialization in the classroom: Implications for equal opportunity. In G. Spindler (Ed.), Doing the ethnography of schooling (pp. 268-309). Prospect Heights, IL: Waveland Press.

Wilensky, U., \& Stroup, W. (1999). Participatory simulations: Network-based design for systems learning in classrooms. In Proceedings of the conference on computer-supported collaborative learning, CSCL ' 99 , Stanford University.

Wilensky, U., \& Stroup, W. (2000). Networked gridlock: Students enacting complex dynamical phenomena with the HubNet architecture. In: Proceedings of the fourth annual international conference of the learning sciences, Ann Arbor, MI. 